\title{
Immune biomarkers associated with clinical benefit from atezolizumab (MPDL3280a; anti-PD-L1) in advanced urothelial bladder cancer (UBC)
}

\author{
Thomas Powles ${ }^{1 *}$, Dorothee Nickles², Eliezer Van Allen ${ }^{3}$, Colombe Chappey², Wei Zou², Marcin Kowanetz², \\ Edward Kadel ${ }^{2}$, Mitchell Denker ${ }^{2}$, Zachary Boyd ${ }^{2}$, Nicholas Vogelzang ${ }^{4}$, Joseph Kim ${ }^{5}$, Joaquim Bellmunt ${ }^{3}$, \\ Yohann Loriot ${ }^{6}$, Charles G Drake ${ }^{7}$, Carol $\mathrm{O}^{\prime} \mathrm{Hear}^{2}$, Marcella Fasso ${ }^{2}$, Priti Hegde ${ }^{2}$, Sanjeev Mariathasan ${ }^{2}$
}

From 30th Annual Meeting and Associated Programs of the Society for Immunotherapy of Cancer (SITC 2015) National Harbor, MD, USA. 4-8 November 2015

\section{Background}

Atezolizumab (anti-PD-L1) has demonstrated robust clinical activity in UBC [1]. Elevated PD-L1 expression on tumor-infiltrating immune cells (IC) is associated with increased clinical efficacy; however, the contribution of other immune biomarkers is unknown. In this study, we explored tumor-based and circulating biomarkers and their correlation with clinical benefit in atezolizumab-treated patients with UBC.

\section{Methods}

Patients from the UBC cohort $(\mathrm{n}=92)$ of the Phase Ia atezolizumab trial PCD4989g (NCT01375842) served as source population for tumor specimens, plasma and PBMC. Baseline tumor PD-L1 expression was assessed by immunohistochemistry using the SP142 antibody assay optimized to detect PD-L1 on both tumor cells (TC) and IC. RNA gene expression on tumor and PBMC samples was interrogated with a NanoString panel of 800 immune and cancer genes. Sequential blood draws assessed dynamic changes in circulating immune biomarkers in plasma (RBM, Multi-Analyte Platform). Correlation between biomarker expression and 6-month progressionfree survival (PFS; as a measure of clinical benefit) was assessed.

\section{Results}

Baseline gene expression in tumors revealed an effector $\mathrm{T}$ cell signature (including CD8A, GZMA, IFNG) and NK gene signature (NKG2 family members) associated with

'Barts Cancer Institute, Queen Mary University of London, London, UK Full list of author information is available at the end of the article clinical benefit. In contrast, disease progression was associated with either a concomitant presence of the immune signature and an opposing stromal signature (PDPN, COL5A1, etc) or the absence of both signatures. Expression of $\mathrm{T}$ cell effector and immune checkpoint genes (CTLA4, PD-1, TIGIT, LAG3) correlated with PD-L1 expression on IC but not TC. Increased expression of myeloid-derived cytokines (IL-6 and IL-8) in the plasma was associated with lack of clinical benefit. Moreover, on-treatment sampling revealed an increased plasma HCG, CA15-3 and TIMP-1 to be correlated with disease progression. Immune biomarkers associated with PBMC, as well as tumor biomarkers associated with various tumor subtypes, will also be discussed.

\section{Conclusions}

Our findings indicate that clinical benefit (as defined by 6-month PFS) from atezolizumab is influenced by a preexisting CD8+ effector T cell and NK cytolytic gene signature in the tumor, which correlated with IC PD-L1 expression. Increased stromal and myeloid-derived cytokine expression in tumor and plasma, respectively, were associated with lack of clinical benefit, underscoring the complex interplay among immunological components in UBC. These components may be conceivable targets to overcome potential resistance and promote response to atezolizumab.

ClinicalTrials.gov Identifier: NCT01375842

\footnotetext{
Authors' details

${ }^{1}$ Barts Cancer Institute, Queen Mary University of London, London, UK. ${ }^{2}$ Genentech, Inc., South San Francisco, CA, USA. ${ }^{3}$ Dana-Farber Cancer Institute, Boston, MA, USA. ${ }^{4}$ US Oncology Research, Comprehensive Cancer
} 
Centers, Las Vegas, NV, USA. ${ }^{5}$ Yale Cancer Center, New Haven, CT, USA.

${ }^{6}$ Gustav Roussy Institute of Oncology, Paris-Sud University, Paris, France.

${ }^{7}$ Department of Oncology, Sidney Kimmel Comprehensive Cancer Center at

Johns Hopkins University, Baltimore, MD, USA.

Published: 4 November 2015

\section{Reference}

1. Powles T, Eder JP, Fine GD, Braiteh FS, Loriot Y, Cruz C, et al: MPDL3280A (anti-PD-L1) treatment leads to clinical activity in metastatic bladder cancer. Nature 2014, 515(7528):558-562.

doi:10.1186/2051-1426-3-S2-P83

Cite this article as: Powles et al:: Immune biomarkers associated with

clinical benefit from atezolizumab (MPDL3280a; anti-PD-L1) in advanced

urothelial bladder cancer (UBC). Journal for ImmunoTherapy of Cancer 20153

(Suppl 2):P83.

\section{Submit your next manuscript to BioMed Central} and take full advantage of:

- Convenient online submission

- Thorough peer review

- No space constraints or color figure charges

- Immediate publication on acceptance

- Inclusion in PubMed, CAS, Scopus and Google Scholar

- Research which is freely available for redistribution

Submit your manuscript at www.biomedcentral.com/submit 